\title{
Influence of the Cholinergic Agonist SDZ 210-086 on Sleep in Healthy Subjects
}

Fritz Hohagen, M.D., Dieter Riemann, Ph.D., René Spiegel, Ph.D., Markus Holzhauer, M.D., and Mathias Berger, M.D.

The administration of $1.0 \mathrm{mg} S D Z 210-086$, an orally acting muscarinic agonist, shortened rapid-eye movement (REM) latency, increased REM percent of sleep period time and the total duration of REM sleep, and decreased slow-wave sleep in 12 healthy male subjects. The administration of $0.5 \mathrm{mg}$ SDZ 210-086 had no statistically significant effect on sleep variables. Although the tonic components of REM sleep (REM duration, the REM percent of sleep period time) were increased,
REM density percent (total) was significantly decreased due to the prolongation of total REM duration (in minutes) and a parallel reduction of the total number of eye movements. This finding is in contrast to studies using other cholinomimetics (i.e., physostigmine, arecoline, and RS 86) and may implicate different generating systems of phasic and tonic REM sleep components. [Neuropsychopharmacology 9:225-232, 1993]
KEW WORDS: SDZ 210-086; Muscarinic agonist; Cholinergic system; Rapid-eye movement sleep

Considerable evidence from both animal and human studies implicates the cholinergic system in the generation of rapid-eye movement (REM) sleep. The administration of cholinomimetics such as galanthamine (Riemann et al. unpublished data) and physostigmine (Sitaram et al. 1976, 1977; Berger et al. 1983), two cholinesterase inhibitors, and muscarinic agonists such as arecoline (Sitaram et al. 1984), RS-86 (Spiegel, 1984; Riemann et al. 1988), and pilocarpine (Berkowitz et al. 1990) shortened REM latency in normal volunteers. Biperiden, a preferential M1 antagonist increased REM sleep latency and reduced REM sleep time in healthy volunteers (Salin-Pascual et al. 1991; unpublished data).

From the Sleep Laboratory at the Psychiatric Department of the University of Freiburg (FH, MB), Freiburg; the Central Institute of Mental Health (DR, MH), Mannheim, Germany; and Sandoz Pharma Ltd. (RS), Basel, Switzerland.

Address correspondence to: Dr. F. Hohagen, Psychiatric Department of the University of Freiburg, Hauptstrasse 5, 7800 Freiburg, Germany.

Received August 4, 1992; revised June 11, 1993; accepted June 18, 1993.
Intracerebral injection of cholinergic agonists into the pontinoreticular formation in animals induced REM sleep (Hobson et al. 1986). Results from animal studies support the hypothesis that REM sleep is promoted by cholinergic cells located mainly in the pontinoreticular formation which show increased activity during REM sleep and that REM sleep is inhibited by noradrenergic and serotonergic neurons located in the locus ceruleus and in the raphe nuclei respectively, which show decreased activity during this sleep stage (Hobson et al. 1975, 1986). Little is known, however, about the specific mechanisms generating the phasic or tonic components of REM sleep. Data on animals indicate (VelazquezMoctezuma et al. 1989, 1990) that the M1 receptor is involved in the desynchronization of the electroencephalogram (EEG), whereas the M2 receptors are responsible for the generation of muscle atonia. According to this study, nicotine receptors seem to be involved in the generation of pontogeniculooccipital (PGO) waves and, therefore, may play a role in the generation of phasic events such as eye movements (Velazquez-Moctezuma et al. 1990).

Studying the effects of cholinergic agonists on REM sleep regulation is of special interest in research on depression and other psychiatric disorders because the 
effects of cholinergic agonists on sleep parameters in healthy volunteers mimic some of the sleep abnormalities that are characteristic of depression, such as shortened REM latency, prolonged duration and heightened density of the first REM period, and reduced slow-wave sleep (SWS) activity (Gillin et al. 1984). Some of the findings obtained can be interpreted within the framework of the "cholinergic-adrenergic" hypothesis of depression proposed by Janowsky and coworkers (1972) that postulates an imbalance between central nervous cholinergic and noradrenergic transmitter systems underlying mania and depression. Rapid-eye movement sleep abnormalities in depression could thus be interpreted as indirect evidence of a muscarinic supersensitivity in affective disorders.

Orally acting cholinergic agonists (e.g., RS 86) are particularly suitable for testing the cholinergic regulation of REM sleep (Berger et al. 1989), and, therefore, newly available putative cholinergic substances should be tested for their central nervous activity in man. The aim of the present study was to test the effect of the compound SDZ 210-086 on sleep and mood of healthy volunteers. In animal studies, the dioxolan analogue SDZ 210-086, [(- )-(2S)- 2,8-dimethyl-1,3-dioxa-8-azaspiro(4.5)decane], was shown to be a specific muscarinic agonist lacking nicotinic as well as acetylcholinesterase inhibitory activity (JM Palacios unpublished data). In animal studies, SDZ 210-086 was shown to have properties similar to those of RS 86 (Palacios et al. 1986), a muscarinic agonist previously used for sleep EEG studies by our group. Although SDZ 210-086 is a potent and selective muscarinic agonist, receptor-binding assays demonstrate that the substance lacks selectivity for the M1 or M2 receptor subtypes (Hammer and Giachetti 1982). SDZ 210-086 does not interact with other neurotransmitter receptors, indicating its specificity for muscarinic receptors. The substance, which can be administered orally, has a half-life of approximately 8 hours in man (unpublished data) and was well tolerated by young male volunteers in single oral doses up to $2 \mathrm{mg}$. Higher doses caused nausea, sweating, and feelings of malaise.

The assumption underlying the present study was that SDZ 210-086 should demonstrate, at well-tolerated doses, effects on REM sleep parameters in man that are similar to those of other cholinergic agents: shortening of REM latency, increased REM sleep during the first hours of sleep, and changes in REM density.

\section{SUBJECTS AND METHODS}

\section{Design}

Subjects slept in the sleep laboratory for 5 consecutive nights. Night 1 served as the adaptation period to the laboratory and was excluded from the data analysis.
The second and fourth laboratory nights, in which placebo was administered, will be referred to as night 2 and night 4 in all of the tables. The drug nights will be referred to as $0.5-\mathrm{mg}$ or $1.0-\mathrm{mg}$ night. Half of the subjects received $0.5 \mathrm{mg} \mathrm{SDZ} \mathrm{210-086} \mathrm{on} \mathrm{night} 3$ and $1.0 \mathrm{mg} \mathrm{SDZ} 210-086$ on night 5 , whereas the remaining six subjects received the two doses in reverse order. Distribution was random. The probands were blind to the study design, as were the experimenters dealing with the subjects during the sleep recordings. Placebo or SDZ $210-086$ was given at 21.30 hours.

\section{Subjects}

Twelve male subjects aged $39.7 \pm 10.8$ years who agreed to participate in the study and were paid for their services were selected as follows: six subjects were between 20 and 40 years old and six were between 41 and 60 years. This configuration in two age groups was chosen to enable us to study the influence of age on the response to SDZ 210-086. Prior to entry into the study, all subjects were carefully screened for physical and mental health. Each subject underwent a physical examination, an EEG, an electrocardiogram, drug-screening, laboratory tests, and an extensive psychiatric interview. Only subjects who were free of medical and psychiatric disorders, had no family history of psychiatric disorders, and whose regular sleep-wake cycle was similar to thelights-out (11 PM) and lights-on (7 AM) schedule in our laboratory were included. All subjects received detailed information about the experimental procedures and possible side effects of the drug and gave their written consent. The research protocol was approved by the university ethics committee.

\section{Mood Assessment}

Before retiring and after waking up in the morning, subjects completed an adjective checklist (AMS) (von Zerssen 1986) to assess mood.

\section{Sleep}

Sleep was recorded between lights out (11:00 PM) and lights on (7:00 AM) by means of standard procedures. HorizontalEOG, submental EMG, and EEG (= C3-A2, C4-A1) were recorded at a paper speed of $10 \mathrm{~mm} / \mathrm{sec}$. Two experienced raters, blind to the condition, scored the recordings according to standardized criteria (Rechtschaffen and Kales 1968).

Records were evaluated for the following sleep parameters:

1) Sleep efficiency: ratio of total sleep time (TST) to time in bed (TIB) $\times 100 \%$

2) Awake stages 1, 2, 3, and 4; SWS (stages 3 and 4 
combined); and REM, all expressed in percent of sleep period time (SPT $=$ time from sleep onset until final awakening).

3) Latencies: time from the beginning of the recording to the first epoch of stage 2 (sleep onset latency) and from sleep onset to the first epoch of stage REM (REM latency) in minutes.

4) Number of awakenings during SPT (at least one epoch of stage wake).

5) Early morning awakening (EMA) in minutes: that is, length of time between the last epoch of stages, $2,3,4$, and REM occurring during the recording and lights on in the morning.

6) REM density for each REM period and for the whole night (REM density is defined as the ratio of 3-second miniepochs including eye movements to the total number of 3-second miniepochs per REM period $x$ $100 \%)$.

7) REM sleep (in minutes): that is, the total duration of REM sleep in minutes for the whole night and for each single REM period.

8) Duration of each non-REM interval (in minutes) for the whole night.

\section{Statistical Analysis}

For descriptive statistics, means \pm standard deviation (SD) were calculated. In a first step of the analysis, the two placebo nights were compared. As there were significant differences between the two placebo nights (see results) that may have been due to carryover effects in night 4 , only the first placebo night was compared to the drug nights. An analysis of variance (ANOVA) with the factor-repeated measurement was calculated for all relevant sleep variables for the placebo night, the $0.5-\mathrm{mg}$ night, and the $1.0-\mathrm{mg}$ night. The ANOVA was corrected according to the method of GreenhouseGeisser. For ANOVAs with a $p$ value $<.10$, two-tailed t-tests were calculated to determine differences between the placebo night and the two drug nights. For all calculations, the level of significance was set at 5\% (twotailed).

\section{RESULTS}

In the first step of the analysis, the two placebo nights (night

cent of SPT, total REM density percent, and the total number of eye movements during the whole night were significantly decreased on night 4 compared with night 2. There was also a strong statistical trend toward a decrease of SWS percent of SPT on night 4 . As these differ- ences may be indicative of a carryover effect of SDZ210086 on night 4 , further analysis dealt only with night 2 .

\section{Effects of SDZ 210-086 on Sleep}

Table 2 displays mean values \pm SD of the sleep variables and the results of the statistical analysis. For variables of sleep continuity, the only significant effect in the ANOVA occurred for time awake percent of SPT. Wake time was almost significantly enhanced under 0.5 mg SDZ 210-086 compared with placebo conditions.

For variables of sleep architecture, a significant ANOVA was obtained for SWS percent of SPT, although there was a statistical tendency for stage 3 percent of SPT. Calculating contrasts (drug nights vs. placebo) for $0.5 \mathrm{mg} \mathrm{SDZ}$, only statistical tendencies occurred, whereas stage 3 percent of SPT and SWS percent of SPT were significantly decreased after the dose of $1.0 \mathrm{mg}$.

For REM sleep, the ANOVA showed significant effects for REM (in minutes), REM percent of SPT, REM latency (in minutes), REM density (percent) of the second REM period, and total REM density (percent). Calculating contrasts (drug nights vs. placebo) for REM (in minutes) and REM percent of SPT, no significant increase was observed under $0.5 \mathrm{mg}$, although the administration of $1.0 \mathrm{mg}$ increased both variables almost significantly. A significant decrease of REM latency was observed only under $1.0 \mathrm{mg}$ but not under $0.5 \mathrm{mg}$ (Figure 1). The eye movement density of the second REM period showed a statistical tendency to decrease after $0.5 \mathrm{mg}$, whereas following $1.0 \mathrm{mg}$, the decrease reached statistical significance. For total REM density, a dosedependent significant decrease of REM density was observed. However, when looking at the total number of eye movements during the whole night no significant decrease of the eye movements was observed.

Figure 2 illustrates the impact of SDZ 210-086 on the non-REM-REM pattern up to the end of the fourth REM period (subsequent cycles were omitted due to decreasing case numbers). As mentioned above, REM latency (expressed as non-REM 1) was shortened after both doses, reaching statistical significance with the dose of $1.0 \mathrm{mg}$ SDZ 210-086. The subsequent non-REM intervals were also decreased under $1.0 \mathrm{mg}$ SDZ 210086 , but the reduction did not reach the $5 \%$ level of significance.

Figure 3 displays the data for REM latency when splitting up the sample into two age groups (I: 20 to 40 years, $n=6$; II: 41 to 60 years, $n=6$ ). Distribution of REM latency in both age groups was similar during placebo and both drug conditions. Statistical analysis of the variables REM (in minutes), REM (percent of SPT), REM latency, and REM density when splitting up the sample in two age groups did not reveal any significant age effect on sleep variables. 
Table 1. Comparison of Sleep Variables ${ }^{a}$ of the Two Placebo Conditions

\begin{tabular}{|c|c|c|c|c|}
\hline & \multirow[b]{2}{*}{ Night 2} & \multirow[b]{2}{*}{ Night 4} & \multicolumn{2}{|c|}{$t$-Test (two-tailed) } \\
\hline & & & $t$ & $p<$ \\
\hline \multicolumn{5}{|l|}{ Sleep continuity } \\
\hline Sleep efficiency percent & $93.3 \pm 2.7$ & $92.0 \pm 4.3$ & 1.13 & $n s^{b}$ \\
\hline Sleep latency $\mathrm{min}$ & $18.5 \pm 10.1$ & $19.6 \pm 15.2$ & -0.24 & ns \\
\hline No. awakenings & $10.0 \pm 7.4$ & $10.2 \pm 10.0$ & -0.06 & ns \\
\hline Time awake percent SPT & $2.8 \pm 2.1$ & $3.4 \pm 2.6$ & -0.92 & ns \\
\hline Early morning awakening min & $0.2 \pm 0.4$ & $1.9 \pm 3.2$ & -1.78 & ns \\
\hline \multicolumn{5}{|l|}{ Sleep architecture } \\
\hline Stage 1 percent SPT & $8.2 \pm 4.1$ & $7.5 \pm 3.3$ & 0.57 & ns \\
\hline Stage 2 percent SPT & $59.8 \pm 5.2$ & $51.8 \pm 10.5$ & 3.06 & 0.01 \\
\hline Stage 3 percent SPT & $3.6 \pm 3.8$ & $3.5 \pm 4.6$ & 0.21 & ns \\
\hline Stage 4 percent SPT & $0.8 \pm 2.5$ & $0.3 \pm 1.0$ & 1.14 & ns \\
\hline Stage SWS percent SPT & $4.4 \pm 5.8$ & $3.8 \pm 5.5$ & 1.85 & 0.10 \\
\hline \multicolumn{5}{|l|}{ REM sleep } \\
\hline REM min & $102.8 \pm 25.0$ & $99.7 \pm 19.7$ & 0.47 & ns \\
\hline REM percent SPT & $23.1 \pm 6.0$ & $23.2 \pm 5.1$ & -0.04 & ns \\
\hline No. REM periods & $4.2 \pm 1.1$ & $3.9 \pm 0.7$ & 0.63 & ns \\
\hline REM Latency $\min (=1$. non-REM interval) $\min$ & $88.8 \pm 51.2$ & $80.0 \pm 36.2$ & 0.81 & ns \\
\hline 2nd Non-REM-Interval min & $85.4 \pm 20.3$ & $89.6 \pm 20.8$ & -0.70 & ns \\
\hline 3rd Non-REM-Interval min & $70.3 \pm 25.6(n=11)$ & $81.0 \pm 20.1$ & -0.86 & ns \\
\hline 4th Non-REM-Interval min & $62.1 \pm 20.1(n=9)$ & $59.2 \pm 14.1(n=9)$ & -0.96 & ns \\
\hline 1st REMP-duration min & $22.5 \pm 10.8$ & $17.0 \pm 8.6$ & 1.52 & ns \\
\hline 2nd REMP-duration min & $26.1 \pm 20.6$ & $36.0 \pm 12.0$ & -1.51 & ns \\
\hline 3rd REMP-duration min & $24.5 \pm 13.6(n=11)$ & $31.9 \pm 12.7$ & -1.02 & ns \\
\hline 4th REMP-duration min & $40.6 \pm 25.4(n=9)$ & $32.7 \pm 17.1(n=9)$ & 0.47 & ns \\
\hline 1st REM-density percent & $14.0 \pm 9.3$ & $13.1 \pm 7.3$ & 0.33 & ns \\
\hline 2nd REM-density percent & $20.5 \pm 7.2$ & $18.6 \pm 6.0$ & 0.71 & ns \\
\hline 3rd REM-density percent & $19.2 \pm 10.3(n=11)$ & $16.7 \pm 8.6$ & 0.61 & ns \\
\hline 4th REM-density percent & $20.1 \pm 8.5(n=9)$ & $18.6 \pm 8.2(n=9)$ & 1.18 & ns \\
\hline Total REM-density percent & $20.9 \pm 5.0$ & $16.8 \pm 4.3$ & 3.10 & 0.01 \\
\hline 1st REMP no. eye movements & $62.8 \pm 53.4$ & $38.3 \pm 30.4$ & 1.86 & 0.10 \\
\hline 2nd REMP no. eye movements & $92.2 \pm 75.0$ & $127.3 \pm 71.2$ & -1.11 & ns \\
\hline 3rd REMP no. eye movements & $92.3 \pm 81.4(n=11)$ & $92.8 \pm 60.6$ & 0.17 & ns \\
\hline 4th REMP no. eye movements & $163.0 \pm 123.4(n=9)$ & $99.8 \pm 46.4$ & 1.18 & ns \\
\hline Total no. eye movements & $423.5 \pm 146.6$ & $339.3 \pm 113.4$ & 2.20 & 0.05 \\
\hline
\end{tabular}

a Data are presented as means \pm SD.

${ }^{\mathrm{b}} \mathrm{ns}=$ not significant.

\section{Effects of SDZ 210-086 on Mood and Safety Data}

No statistically significant influence of $0.5 \mathrm{mg}$ or $1.0 \mathrm{mg}$ SDZ 210-086 was observed on well-being compared to placebo. There were no significant changes in laboratory values after the study. No adverse effects occurred. There was no evidence of a change in blood pressure or ventricular rate after administration of $0.5 \mathrm{mg}$ or 1.0 mg SDZ 210-086 compared to placebo.

\section{DISCUSSION}

The principal finding of this study is that SDZ 210-086 showed a dose-dependent REM sleep stimulating effect with the higher dose, causing a significant reduction of REM latency and an almost significant increase of total REM sleep duration and REM percent of SPT. Furthermore, $1.0 \mathrm{mg}$ SDZ 210-086 significantly reduced SWS.

The shortening of REM latency under the 1.0-mg dose of SDZ 210-086 is in line with comparable studies using physostigmine (Sitaram et al. 1976, 1977; Berger et al. 1983), galanthamine (Riemann et al. unpublished data), arecoline (Sitaram et al. 1978a, 1978b), and RS 86 (Spiegel 1984; Riemann et al. 1988) in healthy subjects. An increase of REM percent of SPT was also observed under cholinergic stimulation with $1.5 \mathrm{mg}$ RS 86 in healthy probands (Riemann et al. 1988). A 1.0-mg dose of SDZ 210-086 displayed characteristics similar to those of RS 86. The main REM sleep-inducing effect was observed at the beginning of the night, although the substance has a longer half-life (approximately 8 
Table 2. Influence of 0.5 to $1.0 \mathrm{mg} \mathrm{SDZ} \mathrm{210-086} \mathrm{on} \mathrm{Sleep} \mathrm{Variables} \mathrm{in} \mathrm{Comparison} \mathrm{to} \mathrm{Placebo} \mathrm{and}$ Results of the Statistical Analysis

\begin{tabular}{|c|c|c|c|c|c|}
\hline & \multirow{2}{*}{$\begin{array}{c}\text { Placebo } \\
\text { (night 2) } \\
1\end{array}$} & \multirow{2}{*}{$\begin{array}{c}0.5 \mathrm{mg} \mathrm{SDZ} \\
2\end{array}$} & \multirow{2}{*}{$\begin{array}{c}1.0 \mathrm{mg} \text { SDZ 210-086 } \\
3\end{array}$} & \multicolumn{2}{|c|}{$\begin{array}{c}\text { ANOVA } \\
d f=2\end{array}$} \\
\hline & & & & $F=$ & $\boldsymbol{P}<$ \\
\hline \multicolumn{6}{|l|}{ Sleep continuity } \\
\hline Sleep efficiency percent & $93.3 \pm 2.7$ & $91.0 \pm 5.7$ & $93.9 \pm 3.9$ & 2.53 & $n s^{1}$ \\
\hline Sleep latency min & $18.5 \pm 10.1$ & $17.5 \pm 14.6$ & $16.3 \pm 10.3$ & 0.18 & ns \\
\hline No. awakenings & $10.0 \pm 7.4$ & $11.7 \pm 9.3$ & $8.1 \pm 6.6$ & 1.68 & ns \\
\hline Time awake percent SPT & $2.8 \pm 2.1$ & $4.5 \pm 2.8$ & $2.6 \pm 2.7$ & 3.50 & 0.05 \\
\hline Early morning awakening min & $0.2 \pm 0.4$ & $4.5 \pm 11.7$ & $0.7 \pm 1.7$ & 1.42 & ns \\
\hline \multicolumn{6}{|l|}{ Sleep architecture } \\
\hline Stage 1 percent SPT & $8.2 \pm 4.1$ & $7.1 \pm 3.2$ & $6.7 \pm 3.2$ & 0.83 & ns \\
\hline Stage 2 percent SPT & $59.8 \pm 5.2$ & $56.5 \pm 6.1$ & $56.7 \pm 6.7$ & 1.72 & ns \\
\hline Stage 3 percent SPT & $3.6 \pm 3.8$ & $1.8 \pm 2.2^{(\star)}$ & $1.7 \pm 3.5$ * & 3.28 & 0.10 \\
\hline Stage 4 percent SPT & $0.8 \pm 2.5$ & $0.5 \pm 1.7$ & $0.3 \pm 1.0$ & 1.39 & ns \\
\hline Stage SWS percent SPT & $4.4 \pm 5.8$ & $2.3 \pm 3.6^{(\star)}$ & $1.9 \pm 4.4^{\star \star}$ & 4.99 & 0.05 \\
\hline \multicolumn{6}{|l|}{ REM sleep } \\
\hline REM min & $102.8 \pm 25.0$ & $105.4 \pm 18.4$ & $123.8 \pm 24.4^{(*)}$ & 3.94 & 0.05 \\
\hline REM percent SPT & $23.1 \pm 6.0$ & $24.1 \pm 4.7$ & $27.4 \pm 5.6^{(\star)}$ & 3.32 & 0.05 \\
\hline No. REM Periods & $4.2 \pm 1.1$ & $4.6 \pm 0.8$ & $4.8 \pm 1.0$ & 2.26 & ns \\
\hline REM latency $\min$. & $88.8 \pm 51.2$ & $65.5 \pm 33.3$ & $58.1 \pm 36.5$ * & 3.68 & 0.05 \\
\hline 2nd Non-REM-Interval min & $85.4 \pm 20.3$ & $76.1 \pm 21.9$ & $72.3 \pm 21.8$ & 1.98 & ns \\
\hline 3rd Non-REM-Interval min & $70.3 \pm 25.6(n=11)$ & $73.8 \pm 15.5$ & $64.3 \pm 11.7$ & 0.82 & ns \\
\hline 4th Non-REM-Interval min & $62.1 \pm 20.1(n=9)$ & $62.4 \pm 12.7(n=11)$ & $57.1 \pm 8.7(n=11)$ & 0.28 & ns \\
\hline 1st REMP-duration min & $22.5 \pm 10.8$ & $25.4 \pm 25.3$ & $31.8 \pm 23.4$ & 0.87 & ns \\
\hline 2nd REMP-duration min & $26.1 \pm 20.6$ & $22.5 \pm 10.7$ & $20.0 \pm 12.0$ & 0.56 & ns \\
\hline 3rd REMP-duration min & $24.5 \pm 13.6(n=11)$ & $32.5 \pm 20.7$ & $36.7 \pm 29.6$ & 0.97 & ns \\
\hline 4th REMP-duration min & $40.6 \pm 25.4(n=9)$ & $31.3 \pm 20.3(n=11)$ & $35.6 \pm 26.9(n=11)$ & 0.90 & ns \\
\hline 1st REM-density percent & $14.0 \pm 9.3$ & $12.2 \pm 8.6$ & $11.3 \pm 5.4$ & 0.49 & ns \\
\hline 2nd REM-density percent & $20.5 \pm 7.2$ & $15.9 \pm 4.4^{(*)}$ & $12.4 \pm 6.8^{\star \star}$ & 6.83 & 0.01 \\
\hline 3rd REM-density percent & $19.2 \pm 10.3(n=11)$ & $16.7 \pm 8.5$ & $15.6 \pm 5.7$ & 1.86 & ns \\
\hline 4th REM-density percent & $20.1 \pm 8.5(n=9)$ & $14.3 \pm 6.0(n=11)$ & $16.5 \pm 8.6(n=11)$ & 1.58 & ns \\
\hline Total REM-density percent & $20.9 \pm 5.0$ & $16.0 \pm 5.0$ * & $15.3 \pm 4.6^{\star \star \star}$ & 10.62 & 0.01 \\
\hline 1st REMP no. eye movements & $62.8 \pm 53.4$ & $81.7 \pm 137.9$ & $70.0 \pm 55.8$ & 0.21 & ns \\
\hline 2nd REMP no. eye movements & $92.2 \pm 75.0$ & $59.2 \pm 25.9$ & $54.6 \pm 62.7$ & 1.67 & ns \\
\hline 3rd REMP no. eye movements & $92.3 \pm 81.4(n=11)$ & $77.7 \pm 51.2$ & $97.2 \pm 72.5$ & 0.17 & ns \\
\hline 4th REMP no. eye movements & $163.0 \pm 123.4(n=9)$ & $93.4 \pm 89.9(n=11)$ & $96.5 \pm 76.6(n=11)$ & 2.04 & ns \\
\hline Total no. eye movements & $423.5 \pm 146.6$ & $337.4 \pm 129.3$ & $376.3 \pm 124.1$ & 2.60 & ns \\
\hline
\end{tabular}

a Data are presented as means $\pm \mathrm{SD}$.

${ }^{\mathrm{b}}$ Contrasts (drug nights vs. placebo): $\mathrm{ns}=$ not significant; ${ }^{(\star)} p<.1{ }^{\star}{ }^{\star} p<.05 ;{ }^{\star \star} p<.01 ;{ }^{\star \star \star} p<.001$.

hours vs. 4 to 6 hours for RS 86; see Palacios et al. 1986). Comparable to RS 86, the first non-REM period ( = REM latency) and the second non-REM period were shortened, leading to a shift of the first REM-non-REM cycle and the induction of further REM periods at the end of the night. The SWS suppressing effect observed for $1.0 \mathrm{mg}$ SDZ $210-086$ is not common to all cholinomimetic drugs. Although a decrease of SWS in healthy subjects was reported under physostigmine (Sitaram et al. 1976), glanthamine (Riemann et al. submitted a), pilocarpine (Berkowitz et al. 1990), and RS 86 (Spiegel 1984; Riemann et al. 1988), no effect on SWS was found with arecoline (Sitaram et al. 1978a, 1978b) or SDZ ENA 713 (Holsboer-Trachsler et al. 1993). The amount of SWS in the present sample was rather low compared with other studies, especially in comparison to our study with RS 86 (Riemann et al. 1988). Because there was no age difference between the samples (RS 86 study: mean age $41.8 \pm 15.6$ years; SDZ 210-086 study: mean age $39.7 \pm 10.8$ years), age may not account for the low amount of SWS found in the present study. Most probably the low amount of SWS may have been due to a selection bias in this relatively small sample.

Although the effect of cholinomimetic drugs on REM latency is well documented in healthy subjects as well as in depressed patients (Gillin et al. 1991), only two cholinergic compounds increase REM density in normal subjects. The administration of physostigmine (Sitaram et al. 1976, 1977), arecoline (Sitaram et al. 1978a, 1978b), pilocarpine (Berkowitz et al. 1990), and 


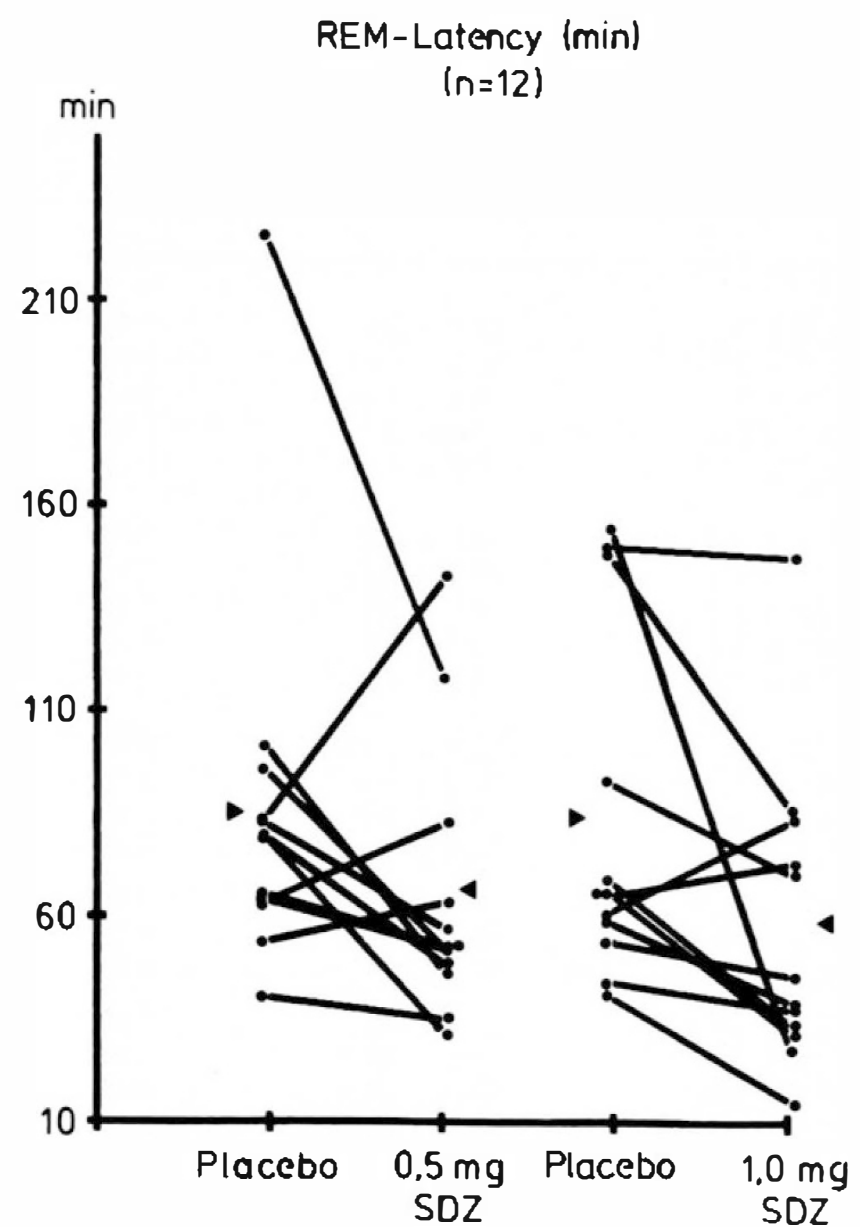

Figure 1. Influence of 0.5-mg and 1.0-mg dose of SDZ 210086 on REM latency in comparison to placebo. Arrows mark medians.

RS 86 (Riemann et al. 1988) did not provoke changes in REM density in healthy subjects. Increased REM density in healthy probands has been reported for SDZ ENA 173 (Holsboer-Trachsler et al. 1993) and galanthamine (Riemann et al. submitted a), with both of these drugs being acetylcholinesterase inhibitors. In contrast to SDZ-ENA 713 and galanthamine, which enhanced REM density, and the other cholinomimetics, which did not influence REM density, both doses of SDZ 210-086 decreased total REM density and simultaneously increased absolute REM sleep duration. Total REM density in the present study was defined as the quotient of total number of eye movements to total REM duration. The observed decrease of total REM density may have been due to a dissociation between tonic and phasic components of REM sleep. Although SDZ 210086 stimulated the tonic aspects of REM sleep, i.e., the total REM duration, the phasic aspects of REM sleep, i.e., the total number of eye movements were not stimulated. There was a tendency toward a decrease in the total number of eye movements, which failed, however,

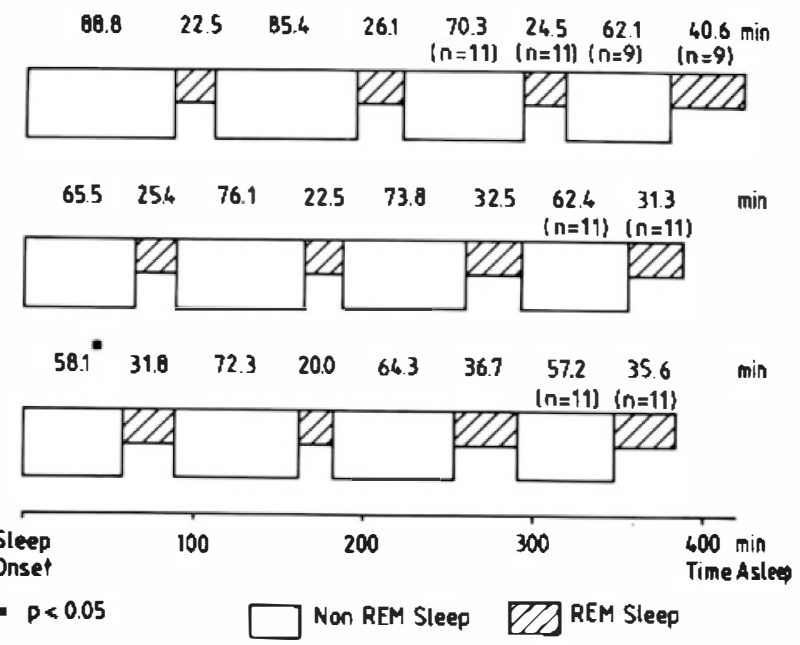

Figure 2. Impact of 0.5-mg and 1.0-mg dose of SDZ 210-086 on the non-REM-REM pattern of 12 healthy subjects.

to reach significance (ANOVA, $p<.11$ ). Several explanations have to be discussed regarding the observed decrease of REM density under cholinergic stimulation. First, a shift of REM episodes due to the shortening of REM latency under cholinergic stimulation with respect to clock time and sleep onset time may induce changes in REM density in REM epoches independent of the drug effect (Zimmermann et al. 1980). Nevertheless, sleep onset time did not differ significantly comparing placebo and drug conditions - sleep latency and time of lights off were not significantly changed. Furthermore, it seems unlikely that the shift of REM episodes with respect to clock time can explain decreased total REM density because this shift also occurred in other studies on cholinomimetic drugs and did not lead to a decrease of total REM density. Second, age may account for changes in REM density. Splitting up the sample into age groups less than or equal to 40 years and older than 40 years, no significant differences could be found between the groups for REM sleep variables. A third explanation may be that SDZ 210-086 tends to act selectively on structures controlling tonic components rather than affecting phasic components of REM sleep. The findings of the simultaneous decrease of REM latency, increase of total REM duration, and decrease of total REM density may implicate different generating systems of phasic and tonic REM sleep aspects. This hypothesis is supported by the finding that another cholinergic compound, SDZ ENA 713, selectively increased only the phasic components of REM sleep: that is, REM density was effected without affecting the tonic aspects of REM sleep and REM latency (HolsboerTrachsler et al. 1993). A recent study showed that different cholinergic receptor subtypes are involved in generating different REM sleep components such as EEG desynchronization, muscle atonia and PGO waves 


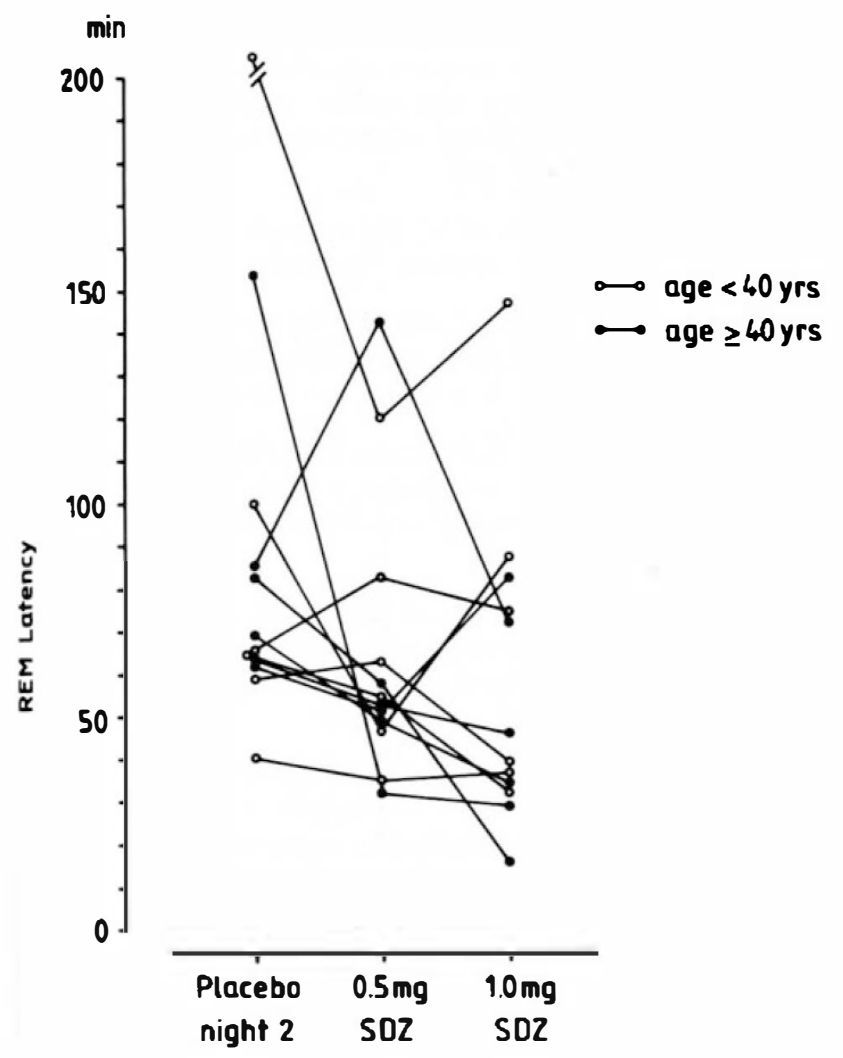

Figure 3. Influence of $0.5-\mathrm{mg}$ and $1.0-\mathrm{mg}$ SDZ $210-086$ on REM latency when splitting up the sample into two age groups.

(Velazquez-Moctezuma et al. 1990). Discussion is warranted as to whether cholinergic agents, depending on their pharmacological profile-differential impact on M1/M2 and nicotinic receptors - may have a differential influence on receptors mediating phasic and tonic aspects of REM sleep.

A dissociation of phasic and tonic REM components was also detected in psychiatric disorders by means of the cholinergic REM induction test: the administration of RS 86 led to a significant shortening of REM latency in depressed patients as well as in patients with chronic schizophrenia (Riemann et al. 1991). Nevertheless, a significant increase of REM density was observed in the depressed patients only, whereas schizophrenic patients did not show alterations of REM density after stimulation with RS 86 (Riemann et al. unpublished data). This finding implies that different components of the REM sleep generators may be disturbed in depressed and schizophrenic patients, pointing to different receptor abnormalities.

The results of our study provide further support for an involvement of the central cholinergic system in the regulation of REM sleep in humans and add indirect evidence for the involvement of the cholinergic system in the pathogenesis of psychiatric disorders. Unfortunately, in another independent tolerance study, SDZ
210-086 provoked an increase of liver enzymes in healthy volunteers. Thus, for reasons of hepatic tolerance, the substance is no longer available for research or clinical purposes. The differential effect of this substance on phasic and tonic components of REM sleep compared with other cholinergic agonists and its possible implication for the understanding of REM sleep abnormalities in psychiatric disorders, however, seemed worth communication.

\section{REFERENCES}

Berger M, Lund R, Bronisch T, von Zerssen D (1983): REM latency in neurotic and endogenous depression and the cholinergic REM induction test. Psychiatry Res 10:113-123

Berger M, Riemann D, Höchli D, Spiegel R (1989): The cholinergic REM sleep-induction-test with RS-86. State or trait marker of depression. Arch Gen Psychiatry 46:421-428

Berkowitz A, Sutton L, Janowsky D, Gillin JC (1990): Pilocarpine, an orally active muscarinic cholinergic agonist, induces REM sleep and reduces delta sleep in normal volunteers. Psychiatry Res 33:113-119

Gillin JC, Sitaram N, Wehr TA, Duncan W, Post RM, Murphy DL, Mendelson WB, Wyatt RJ, Bunney WE, Jr. (1984): Sleep and affective illness. In Post RM and Ballenger JC (eds) Neurobiology of Mood Disorders. Baltimore, Williams and Wilkins, pp 157-189

Gillin JC, Sutton L, Ruiz C, Kelsoe J, Dupont RM, Darko D, Risch SC, Golshan S, Janowsky D (1991): The Cholinergic Rapid Eye Movement Induction Test with Arecoline in Depression. Arch Gen Psychiatry 48:264-270

Hammer R, Giachetti A (1982): Muscarinic receptor subtypes: M1 and M2 biochemical and functional characterization. Life Sci 31:2991-2998

Hobson JA, McCarley RW, Wyzinski PW (1975): Sleep cycle oscillation: Reciprocal discharge by two brain stem neuronal groups. Science 189:55-58

Hobson JA, Lydic R, Baghdoyan HA (1986): Evolving concepts of sleep cycle generation: From brain centers to neuronal populations. Behav Brain Sci 9:371-448

Holsboer-Trachsler E, Hatzinger M, Stohler R, Hemmeter U, Gray J, Müller J, Kocher R, Spiegel R (1993): Effects of the novel acetylcholinesterase inhibitor SDZ ENA 713 on sleep in man. Neuropsychopharmacology 8:87-92

Janowsky DS, El-Jousef MK, Sekerke HJ, Davis JM (1972): A cholinergic-adrenergic hypothesis of mania and depression. Lancet 2:632-635

Palacios JM, Bollinger G, Closse A, Enz A, Gmelin G, Melanowski J (1986): The pharmacological assessment of RS 86 (2-ethyl-8-methyl-2,8-diazaspiro-4,5-decan-1,3-dion hydrobromide). A potent, specific muscarinic acetylcholine receptor agonist. Eur J Pharmacol 125:45-62

Rechtschaffen A, Kales A, eds (1968): A Manual of Standardized Terminology, Techniques and Scoring System for Sleep Stages of Human Subjects. Washington DC, Department of Health, Education, and Welfare

Riemann D, Joy D, Höchli D, Lauer Ch, Zulley J, Berger M 
(1988): Influence of the cholinergic agonist RS 86 on normal sleep: Sex and age effects. Psychiatry Res 24:137-147

Riemann D, Gann H, Fleckenstein P, Hohagen F, Olbrich R, Berger M (1991): The effect of RS 86 on REM latency in schizophrenia. Psychiatry Res 38:89-92

Salin-Pascual RJ, Granados-Fuentes D, Galicia-PoloL, Nieves E, Echeverry J (1991): Biperiden administration in normal sleep and after rapid eye movement sleep deprivation in healthy volunteers. Neuropsychopharmacology 5:97-102

Sitaram N, Wyatt RJ, Dawson S, Gillin JC (1976): REM sleep induction by physostigmine infusion during sleep. Science 191:1281-1286

Sitaram N, Mendelson WB, Wyatt RJ, Gillin JC (1977): The time-dependent induction of REM sleep and arousal by physostigmine infusion during normal human sleep. Brain Res 122:562-567

Sitaram N, Moore AM, Gillin JC (1978a): Experimental acceleration and slowing of REM sleep ultradian rhythm by cholinergic agonist and antagonist. Nature 274:490-492

Sitaram N, Moore AM, Gillin JC (1978b): Induction and resetting of REM sleep rhythm in normal man by arecoline: Blockade by scopolamine. Sleep 1:83-90
Sitaram N, Gillin JC, Bunney WE Jr (1984): Cholinergic and catecholaminergic receptor sensitivity in affective illness: Strategy and theory. In Post RM and Ballenger JC (eds), Neurobiology of Mood Disorders. Baltimore, Williams \& Wilkins pp 629-651

Spiegel R (1984): Effects of RS 86, an orally active cholinergic agonist, on sleep in man. Psychiatry Res 11:1-13

Velazquez-Moctezuma J, Gillin JC, Shiromani J (1989): Effect of specific M1, M2 muscarinic receptor agonists on REM sleep generation. Brain Res 503:128-131

Velazquez-Moctezuma J, Shalauta MD, Gillin JC, Shiromani PJ (1990): Differential effects of cholinergic antagonists on REM sleep components. Psychopharmacol Bull 26: 349-353

von Zerssen D (1986): Clinical Self-rating Scales (CSRS) of the Munich Psychiatry Information System (PSYCHIS München). In Sartorius N and Ban T (eds), Assessment of Depression. Berlin, Springer

Zimmermann JC, Czeisler CA, Laxminarayan S, Knauer RS, Weitzmann ED (1980): REM density is dissociated from REM sleep timing during free-running sleep episodes. Sleep 2:409-415 